\title{
Infant feeding in relation to eating patterns in the second year of life and weight status in the fourth year
}

\author{
Elizheeba C Abraham ${ }^{1}$ *, Jon Godwin ${ }^{1}$, Andrea Sherriff ${ }^{2}$ and Julie Armstrong ${ }^{1}$ \\ ${ }^{1}$ Institute for Applied Health Research, Glasgow Caledonian University, Cowcaddens Road, Glasgow G4 OBA, \\ UK: ${ }^{2}$ Glasgow Dental School, College of Medical Veterinary and Life Sciences, University of Glasgow, \\ Glasgow, UK
}

Submitted 1 September 2011: Final revision received 21 March 2012: Accepted 30 March 2012: First published online 25 May 2012

\begin{abstract}
Objective: To explore associations of early infant feeding with (i) eating patterns in the second year of life and (ii) weight status in the fourth year of life in a prospective cohort of children in Scotland.

Design: Growing Up in Scotland (GUS) longitudinal birth cohort study (2005-2008).

Setting: Scotland, UK.

Subjects: Children aged 9-12 months ( $n$ 5217) followed through to 45-48 months. Results: Infant feeding was associated with eating patterns, defined by using SPSS two-step cluster analysis, in the second year of life. Children who were ever breast-fed compared with never breast-fed (adjusted OR $=1 \cdot 48,95 \%$ CI $1 \cdot 27$, 1.73 ) were more likely to have a positive eating pattern (Cluster 2). Children who started complementary feeding at 4-5 months or 6-10 months compared with 0-3 months (adjusted OR $=1 \cdot 32,95 \%$ CI 1.09, $1 \cdot 59$ or AOR $=1 \cdot 50,95 \%$ CI $1 \cdot 19$, $1 \cdot 89)$ were more likely to belong to Cluster 2 . Breast-feeding was negatively associated with being overweight or obese in the fourth year of life compared with no breast-feeding (adjusted $\mathrm{OR}=0 \cdot 81,95 \%$ CI $0 \cdot 81,1 \cdot 01$ ). Introduction of complementary feeding at 4-5 months compared with 0-3 months was negatively associated with being overweight or obese (adjusted OR $=0 \cdot 74,95 \%$ CI $0 \cdot 57,0 \cdot 97$ ).

Conclusions: Breast-feeding and introduction of complementary feeding after 4 months were associated with a positive eating pattern in the second year of life. Introduction of complementary feeding at 4-5 months compared with 0-3 months was negatively associated with being overweight or obese.
\end{abstract}

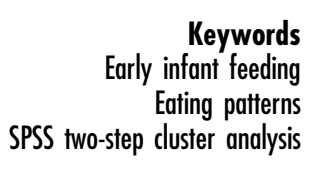

Eating patterns and behaviours in infants and young children are influenced by complex interrelated factors such as cultural beliefs ${ }^{(1)}$, parental or child interactions and feeding styles ${ }^{(2-5)}$, as well as the parent's or primary caregiver's education, experiences, attitudes and social and economic circumstances ${ }^{(6-8)}$.

In addition to nourishing the infant, early feeding practices and diet in the pre-school years play an important role in developing fine motor skills, social skills and communicative skills and may be important in the development of energy balance regulation ${ }^{(9-11)}$. The transition from infant feeding to toddler diet is important as it marks a gradual change in nutritional habits as well as significant social and educational developments ${ }^{(12,13)}$.

Most published research has focused on single behaviours such as breast-feeding ${ }^{(14-17)}$ or timing of introduction to solid foods ${ }^{(17,18))}$. There is little published data about eating patterns immediately following infancy, during the toddler years. However, there is evidence to suggest that at the individual and social level, early experiences of infant or child feeding practices and nutritional quality can play a major role in influencing eating habits and health outcomes of individuals in later life ${ }^{(4,5,14,16,19,20)}$.

In Scotland, poor diet and obesity are a major public health concern ${ }^{(21)}$ and many researchers have reported on the effect of early infant feeding and the risk of childhood overweight or obesity ${ }^{(14,16,20)}$. There is good evidence with plausible mechanisms for breast-feeding being protective against childhood obesity ${ }^{(14,16,20)}$, however most infants in Scotland are either formula-fed or mixed-fed $^{(22)}$. In addition to milk feeding, the timing of complementary feeding and diet following the infancy stage may also be important in optimising growth and development, although this is less well studied ${ }^{(23,24)}$. Two large prospective cohort studies in the UK have identified dietary patterns characterised by highly energy-dense, low-nutrient foods in 1-year-old and 3-year-old children ${ }^{(17,25)}$. This energy-dense type of pattern was shown 
to persist into later childhood ${ }^{(25)}$ and in one of the studies was related to body composition at age 4 years ${ }^{(17)}$.

The present paper aims to add to our understanding of the interrelationships between early feeding experiences characterised by breast-feeding, complementary feeding and patterns of diet in the first few years. This will help to identify the role of early feeding in interventions to prevent obesity and provide better understanding of the associations between early-life dietary experiences with later-life health outcomes. Although there are several methods used to aggregate infants that have similar eating patterns, the present paper uses an exploratory statistical multivariate two-step cluster analysis method, not previously used in this context, on a large and contemporary prospective study of pre-school children.

\section{Methods}

The Growing Up in Scotland (GUS) survey (http:// www.ltscotland.org.uk/earlyyears/cpd/research/gus/index. asp) is a national longitudinal infant cohort study which has been collecting data annually since 2005. Each data collection period is referred to as a 'sweep'. For the purpose of addressing the research questions in the present paper, the GUS Birth Cohort data set was explored. The data set provides data on a representative random sample of Scottish infants, out of a random selection of 130 geographically clustered areas across Scotland. The Child Benefit Records held by the Department of Work and Pensions was used as the sampling frame ${ }^{(26)}$. The infants in the Birth Cohort data set were born between June 2004 and May 2005, and the first sweep of data was collected between April 2005 and May 2006. The survey data were collected using the computer-assisted personal interviewing technique. This involved a study interviewer conducting a face-to-face interview with the child's main caregiver and simultaneously entering the responses directly into a laptop computer. The variables relating to infant feeding, eating patterns, weight status and socio-economic status (SES) were available from: Sweep $1^{(27)}$, collected in April 2005-May 2006 ( $n$ 5217; 9-12 months old); Sweep $2^{\text {(28), }}$ collected in April 2006-May 2007 ( $n$ 4512; aged 19-24 months); and Sweep $4^{(29)}$, collected in April 2008-May 2009 ( $n$ 3994; 45-48 months old). The relevant variables for the analysis were merged together to produce one SPSS (SPSS statistical software package version 17; SPSS Inc., Chicago, IL, USA) working file. The variables are described in Table 1.

\section{Defining infant eating patterns as chsters at 19-24 montbs}

Variables from the Food and Nutrition module of the GUS Sweep 2 ( $n$ 4512; aged 19-24 months) survey which explained infants' or young children's eating patterns were checked for completeness. Variables with >5\% missing responses were excluded from the cluster analysis. The categories used to define frequency of consumption of sweets, crisps or soft drinks were re-coded to quantify consumption per week and used as continuous variables to define the clusters.

The SPSS two-step cluster analysis technique (SPSS version 17) was used to group together children with similar eating patterns, defined by variables recording variety of fruits intake, variety of vegetables intake, snacking behaviour, intake of energy-dense or low-nutrient foods, meal or snack pattern. Unweighted data from fifteen variables were entered into the two-step cluster analysis exploratory statistical procedure. These variables are listed in Fig. 1. The clusters were generated using the SPSS loglikelihood distance measure two-step cluster analysis algorithm. The algorithm used Schwarz's Bayesian information criterion to determine the number of clusters automatically. The program calculated the rank of importance for the categorical variables using Pearson's $\chi^{2}$ test, while Student's $t$ test was used for continuous variables. The resulting clusters generated were labelled by the researcher, using prior knowledge of negative and positive indicators of eating patterns identified from the WHO practical guidance on the frequency and type of food offered to infants aged 6-24 months ${ }^{(30)}$. The cluster membership solution was saved as a new variable to be used for subsequent statistical analysis.

A Forest plot diagram was generated to illustrate the OR and 95\% CI for each of the selected eating pattern variables as predictors of cluster membership (see Fig. 1). The OR and 95\% CI for each category in Fig. 1 were calculated using the formula: $\exp [(O-E) /(V \pm 1 \cdot 96 / \sqrt{V})]$, where $O=$ observed, $E=$ expected and $V=$ variance. In Fig. 1, each OR point is represented by a square whose area is proportional to the logrank variance; thus, larger squares have a greater information content and correspondingly tighter confidence intervals.

\section{Statistical analysis}

The Pearson $\chi^{2}$ test was used to examine the association between infant feeding with eating patterns in the second year of life and SES. Infant feeding was described using the variables breast-feeding and age of starting complementary feeding. Breast-feeding was defined using the question 'Was the child ever breast-fed?' and age of starting complementary feeding was defined using the question 'How many months old when the child started solid food?'. SES was defined using the national Scottish Index of Multiple Deprivation (SIMD) 2006 and respondents' education based on the highest level attained (see Table 1). Binary logistic regression was used to estimate the OR, adjusted OR (AOR) and $95 \% \mathrm{CI}$ for the univariate and multivariate (adjusted for SES) associations between eating patterns, breast-feeding and start of complementary feeding. The outcome variable used was the eating pattern cluster and the explanatory variables were breast-feeding, complementary feeding, SIMD and respondents' education (Table 2). 
Table 1 List of variables used for analysis from Sweep 1, Sweep 2 and Sweep 4 of the Growing Up in Scotland (GUS) Birth Cohort data set

\begin{tabular}{ll}
\hline Variable (Sweep) & Definition \\
\hline $\begin{array}{l}\text { Scottish Index of Multiple Deprivation (SIMD) } \\
\begin{array}{l}\text { Quintile 2006 (Sweep 4, collected } \\
\text { 2008-2009, age 45-48 months) }\end{array}\end{array}$ & $\begin{array}{c}\text { Area-based measure of deprivation. Derived from } \\
\text { the quintiles of SIMD score variables on the } \\
\text { Scottish Health Survey database }\end{array}$ \\
& \\
$\begin{array}{l}\text { Education (Sweep 4, collected 2008-2009, } \\
\text { age 45-48 months) }\end{array}$ & $\begin{array}{l}\text { Highest educational qualification of respondent. } \\
\text { Standard Grade or equivalent qualifications are } \\
\text { taken at the age of 15 or 16 years old. Higher } \\
\text { Grade or equivalent qualifications are taken at } \\
\text { the age of 16 or 17 years old. Vocational } \\
\text { qualifications are provided in further education } \\
\text { colleges through apprenticeship }\end{array}$
\end{tabular}

Breast-feeding (Sweep 1, collected 2005-2006, Was the child ever breast-fed? age 9-12 months)

Age of starting complementary feeding (Sweep 1, collected 2005-2006, age 9-12 months)

Overweight category (includes obese children) based on BMI Z-scores (Sweep 4, collected 2008-2009, age 45-48 months)

Birth weight (Sweep 1, collected 2005-2006, age 9-12 months)

Eating patterns at 19-24 months defined using cluster analysis (Sweep 2, between 2006-2007) solid food?
How many months old when the child started
Coding

$1=$ least deprived

2

3

4

$5=$ most deprived

$1=$ degree or professional qualification or higher

$2=$ vocational qualification below degree

$3=$ higher grade or equivalent

$4=$ standard grade or equivalent

$5=$ other

$6=$ no qualification

$1=$ yes

$2=$ no

Continuous data categorised to:

$1=0-3$ months

$2=4-5$ months

$3=6-10$ months

BMI Z-score cut-offs:

$1=\geq 1 \cdot 04$, overweight/obese

$2=<1 \cdot 04$, not overweight/obese

Continuous variable: weight $(\mathrm{g})$

15 variables which best explained infants' eating patterns. See Fig. 1 for list of variables
$1=$ Cluster 1 (defined as a 'more negative eating pattern')

2 = Cluster 2 (defined as 'positive eating pattern')
The univariate associations between variables that describe early nutrition (breast-feeding, age of starting complementary feeding and eating patterns in the second year of life) with weight status in the fourth year of life were assessed using Pearson's $\chi^{2}$ test. Weight status was based on the UK 1990 BMI references curve ${ }^{(31)}$ and the variable used to classify infants as overweight or obese was defined using the BMI $Z$-score cut-off (BMI $Z$-score $\geq 1 \cdot 04=$ overweight or obese and BMI $Z$-score $<1 \cdot 04=$ not overweight or obese; see Table 1 ). Binary logistic regression was used to estimate the OR, AOR and 95\% CI for the univariate and multivariate (adjusted for SES) associations between weight status and breast-feeding, age of starting complementary feeding and eating pattern cluster. The outcome variable used was weight status at 4 years old and the explanatory variables were breast-feeding, complementary feeding and eating patterns, with birth weight, SIMD and education as potential confounders of the association (see Table 3).

Infants with missing data points within any of the models reported in Table 2 or Table 3 were excluded from the analysis.

\section{Complex sample survey design analysis}

The final Sweep 4 longitudinal survey non-response sample weight was generated using a model-based weighting technique by the GUS team to correct for sampling error and non-response bias. More detail is given in the GUS User Guide for each sweep, which can be accessed from the GUS website (http://www.growingupinscotland.org.uk/) under the 'Publications' section.

The Complex Sample module in SPSS version 17 was used to account for the longitudinal non-response sample weight and the clustering and stratification of the study's complex sample survey design. The clustering and stratification weights were used to correct for unequal sample selection. These weights were then used to create an SPSS complex sample plan file to generate the weighted descriptive and inferential statistics reported in Tables 2 and 3.

\section{Results}

\section{Eating patterns in the second year (19-24 months) of life}

A total of 4493 children ( $86 \%$ of Sweep 1 sample) had complete sets of eating pattern variables and were 


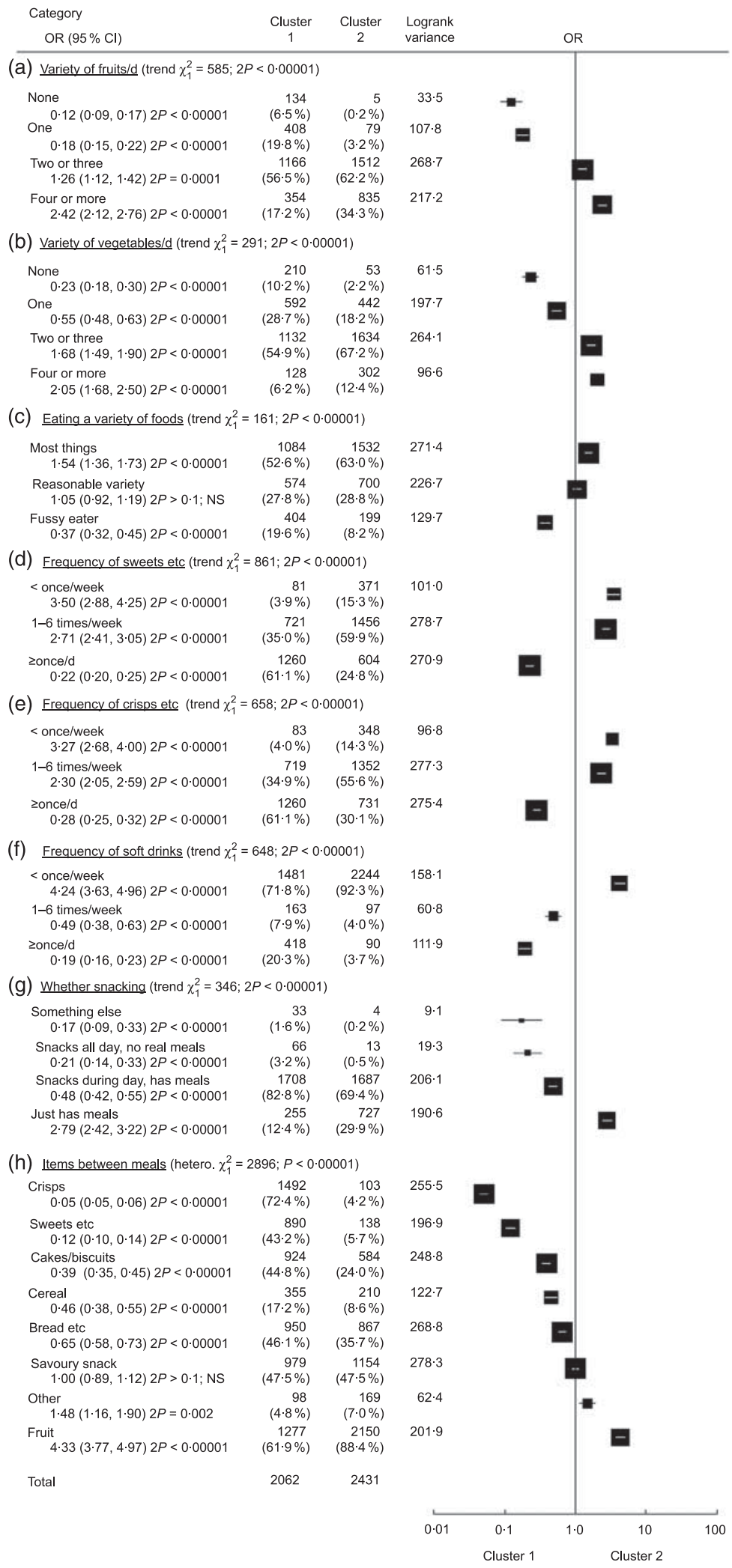

Fig. 1 OR (square symbols) and $95 \% \mathrm{Cl}$ (horizontal lines) for various subgroups of eating patterns in the second year of life as predictors of cluster membership (Cluster $1=$ more negative eating pattern; Cluster 2 = positive eating pattern); Growing Up in Scotland (GUS) Birth Cohort data set. Strong monotonic associations exist between cluster membership and eating patterns in sections $(\mathrm{a})$ to $(\mathrm{g})$ and are indicated by $\chi^{2}$ tests for trend; section $(\mathrm{h})$ also shows high heterogeneity and has been ordered by OR 
Table 2 Univariate and multivariate associations of infant eating pattern cluster in the second year of life (Cluster $1=$ more negative eating pattern; Cluster $2=$ positive eating pattern) with breast-feeding, complementary feeding and socio-economic status variables (respondents' highest attained level of education (Educ) and Scottish Index of Multiple Deprivation (SIMD) 2006) using SPSS (version 17) Complex Sample Pearson $\chi^{2}$ test and logistic regression (Cluster 1 is the reference category); Growing Up in Scotland (GUS) Birth Cohort data set

\begin{tabular}{|c|c|c|c|c|c|c|c|c|c|c|c|c|}
\hline \multirow[b]{2}{*}{ Variable } & \multirow[b]{2}{*}{ Total $(n)$} & \multicolumn{2}{|c|}{$\begin{array}{l}\text { Cluster 1, } \\
\text { weighted }\end{array}$} & \multicolumn{2}{|c|}{$\begin{array}{l}\text { Cluster 2, } \\
\text { weighted }\end{array}$} & \multirow[b]{2}{*}{ Pearson $\chi^{2}$ test } & \multicolumn{2}{|c|}{$\begin{array}{l}\text { Univariable for the } \\
\text { outcome variable }\end{array}$} & \multicolumn{2}{|c|}{ Educ } & \multicolumn{2}{|c|}{ Educ+SIMD } \\
\hline & & $n$ & $\%$ & $n$ & $\%$ & & Unadjusted OR & $95 \% \mathrm{Cl}$ & Adjusted OR & $95 \% \mathrm{Cl}$ & Adjusted OR & $95 \% \mathrm{Cl}$ \\
\hline Breast-feeding & 3825 & 1793 & $46 \cdot 9$ & 2032 & $53 \cdot 1$ & $P<0.001 ; \chi^{2}(1)=139.6$ & & & & & & \\
\hline Ever breast-fed & 2293 & 896 & $39 \cdot 0$ & 1397 & $60 \cdot 9$ & & $2 \cdot 20$ & $1 \cdot 93,2 \cdot 51$ & 1.57 & $1 \cdot 36,1 \cdot 82$ & $1 \cdot 48$ & $1 \cdot 27,1 \cdot 73$ \\
\hline Never breast-fed & 1532 & 897 & $58 \cdot 6$ & 635 & $41 \cdot 4$ & & 1.00 & Ref. & $1 \cdot 00$ & Ref. & 1.00 & Ref. \\
\hline Age of starting complementary feeding & 3766 & 1760 & $46 \cdot 7$ & 2006 & $53 \cdot 3$ & $2 P<0.001 ; \chi^{2}(2)=42 \cdot 6$ & & & & & & \\
\hline $0-3$ months & 583 & 343 & $58 \cdot 8$ & 240 & $41 \cdot 2$ & & $1 \cdot 00$ & Ref. & $1 \cdot 00$ & Ref. & $1 \cdot 00$ & Ref. \\
\hline 4-5 months & 2504 & 1131 & $45 \cdot 2$ & 1373 & $54 \cdot \overline{8}$ & & $1 \cdot 74$ & $1 \cdot 45,2 \cdot 08$ & $1 \cdot 38$ & $1 \cdot 14,1 \cdot 67$ & $1 \cdot 32$ & $1 \cdot 09,1 \cdot 59$ \\
\hline $6-10$ months & 679 & 286 & $42 \cdot 1$ & 393 & $57 \cdot 9$ & & 1.96 & $1 \cdot 56,2 \cdot 47$ & 1.54 & $1 \cdot 23,1.94$ & $1 \cdot 50$ & $1 \cdot 19,1 \cdot 89$ \\
\hline Educ & 3810 & 1782 & $46 \cdot 8$ & 2028 & $53 \cdot 2$ & $2 P<0.001 ; \chi^{2}(5)=248.8$ & & & & & & \\
\hline Degree or equivalent & 1064 & 307 & $28 \cdot 9$ & 757 & $71 \cdot 1$ & & $5 \cdot 31$ & $3 \cdot 89,7 \cdot 26$ & & & & \\
\hline Vocational qualification below degree & 1474 & 719 & $48 \cdot 8$ & 755 & $51 \cdot 2$ & & $2 \cdot 26$ & $1 \cdot 64,3 \cdot 12$ & & & & \\
\hline Higher grade or equivalent & 283 & 135 & $47 \cdot 7$ & 148 & $52 \cdot 3$ & & $2 \cdot 36$ & $1.66,3.35$ & & & & \\
\hline Standard grade or equivalent & 661 & 397 & $60 \cdot 1$ & 264 & $39 \cdot 9$ & & $1 \cdot 43$ & $0.98,2.08$ & & & & \\
\hline Other & 6 & 4 & $66 \cdot 7$ & 2 & $33 \cdot 3$ & & 0.98 & $0 \cdot 19,5 \cdot 04$ & & & & \\
\hline No qualification & 324 & 221 & $68 \cdot 2$ & 103 & $31 \cdot 8$ & & $1 \cdot 00$ & Ref. & & & & \\
\hline SIMD quintile & 3798 & 1781 & $46 \cdot 9$ & 2017 & $53 \cdot 1$ & $2 P<0.001 ; \chi^{2}(4)=129.1$ & & & & & & \\
\hline $0.9449-7 \cdot 7446$ (least deprived) & 693 & 223 & $32 \cdot 2$ & 470 & $67 \cdot 8$ & & $2 \cdot 86$ & $2 \cdot 31,3.54$ & & & & \\
\hline $7 \cdot 7472-13 \cdot 5627$ & 729 & 299 & $41 \cdot 0$ & 430 & $59 \cdot 0$ & & 1.96 & $1 \cdot 56,2 \cdot 45$ & & & & \\
\hline $13 \cdot 5640-21 \cdot 0436$ & 742 & 340 & $45 \cdot 8$ & 402 & $54 \cdot 2$ & & 1.61 & $1.32,1.97$ & & & & \\
\hline $21 \cdot 0521-33 \cdot 6982$ & 705 & 383 & $54 \cdot 3$ & 322 & $45 \cdot \overline{7}$ & & $1 \cdot 14$ & $0.91,1.44$ & & & & \\
\hline 33.7252-89.0941 (most deprived) & 929 & 536 & $57 \cdot 7$ & 393 & 42.3 & & $1 \cdot 00$ & Ref. & & & & \\
\hline
\end{tabular}

Ref., reference category.
Unweighted totals: breast-feeding, Cluster $1=2061$ and Cluster $2=2431$; age of starting complementary feeding, Cluster $1=2021$ and Cluster $2=2401$. 
included in the two-step cluster analysis. Two homogeneous clusters were identified, with each child belonging to one of the clusters. Figure 1 illustrates the relative contributions of the variables, together with the OR and 95\% CI, as predictors of cluster membership. It can clearly be seen how membership of 'Cluster 1 ' ( $n$ 2062; $46 \%$ of sample) is associated with more negative eating patterns than membership of 'Cluster 2' ( $n$ 2431; $54 \%$ of sample), notably in the lower variety of fruit/ vegetable intake daily, the higher frequencies of sweets, crisps and soft drinks and the prevalence of snacking behaviour. Therefore children in Cluster 1 were defined as having a 'more negative eating pattern'. Cluster 2 was characterised by children who consumed a high variety of fruit daily, a high variety of vegetables daily and fruit between meals, and had a higher prevalence of eating just a meal with no snacking; therefore this group was defined as having a 'positive eating pattern'.

\section{Infant feeding and eating patterns in the second year of life}

Within the whole birth cohort $60 \%$ of the infants were breast-fed, $69 \%$ of infants were breast-fed in Cluster 2 compared with $50 \%$ in Cluster 1.

Breast-feeding was significantly associated with Cluster 2. This relationship between breast-feeding and positive eating pattern in the second year of life was attenuated but remained significant after adjusting for SES, i.e. respondents' education and SIMD quintile $(\mathrm{AOR}=1 \cdot 48,95 \%$ CI $1 \cdot 27$, 1.73), Table 2.

The prevalence of infants starting complementary feeding at 0-3 months, 4-5 months and 6-10 months was respectively $20 \%, 64 \%$ and $16 \%$ in Cluster 1 and $12 \%$, $69 \%$ and $20 \%$ in Cluster 2. The age of starting complementary feeding was significantly associated with positive eating pattern in the second year. The adjusted odds for a positive eating pattern in children who started complementary feeding at 4-5 months and 6-10 months was $\mathrm{AOR}=1.32(95 \% \mathrm{CI} 1.09,1.59)$ and $\mathrm{AOR}=1.50$ (95\% CI $1 \cdot 19,1 \cdot 89$ ), respectively (Table 2 ).

\section{Infant or child feeding and weight status in the fourth year of life}

Any breast-feeding was negatively associated with overweight or obesity in the fourth year of life. Infants who were breast-fed were less likely to be overweight or obese $(\mathrm{OR}=0.73,95 \%$ CI $0.59,0.90)$. This association was attenuated after adjusting for birth weight and SES (AOR $=0 \cdot 81,95 \%$ CI $0 \cdot 64,1 \cdot 01)$, Table 3 . Introduction of complementary feeding at 4-5 months compared with 0-3 months had a negative association with overweight or obesity in the fourth year of life $(\mathrm{AOR}=0 \cdot 74,95 \% \mathrm{CI}$ $0.57,0.97$ ), Table 3. No significant relationship was observed between eating patterns in the second year of life and being overweight or obese in the fourth year, Table 3 . 


\section{Socio-economic status and eating patterns}

There was a strong association between eating patterns and respondents' education. Thirty-seven per cent of caregivers whose children were allocated to the positive cluster (Cluster 2) had a degree or equivalent compared with $17 \%$ in the more negative cluster (Cluster 1 ). Where the main caregivers reported their highest education level to be a degree or equivalent, the odds for belonging to the positive cluster was $\mathrm{OR}=5 \cdot 31(95 \%$ CI $3 \cdot 89,7 \cdot 26)$ compared with those with no qualification.

Likewise, $23 \%$ of respondents in Cluster 2 were in the least deprived SIMD quintile while $13 \%$ of respondents in Cluster 1 were in the least deprived SIMD quintile. The odds for belonging to Cluster 2 in the least deprived SIMD quintile was $\mathrm{OR}=2 \cdot 86$ (95\% CI $2 \cdot 31,3 \cdot 54)$ compared with the most deprived.

\section{Discussion}

The present study explored the relationship of early infant feeding (breast-feeding and age of starting complementary feeding) with eating patterns in the second year and weight status in the fourth year of life using a Scottish longitudinal birth cohort. The SPSS two-step cluster analysis technique was used to identify clusters of infants with similar eating patterns in their second year. The application of this technique to identify eating pattern clusters is advantageous, because it allows us to investigate how eating patterns in the second year of life may be influenced by infant feeding decisions and the potential influence they may have on the causal pathway of childhood overweight and obesity. We are not aware of any studies published to date that have used the SPSS two-step cluster analysis technique in this particular age group, to cluster infants according to eating pattern.

In the current study two clusters of infants were identified. Infants in Cluster 2 were predominantly leaning towards a 'positive eating pattern' as defined by a high variety of fruits daily, a high variety of vegetables daily, fruit between meals and higher prevalence of eating just a meal with no snacking. It is well recognised that a key component of healthy eating, in children going through the infancy to toddler diet transition phase, is the variety of healthy food choices available for snacks and meals ${ }^{(32)}$. Also food choices early in life provide an important foundation for diet and nutritional health later in life ${ }^{(33)}$.

\section{Breast-feeding}

Infants who were breast-fed were more than twice as likely to be in Cluster 2 in their second year compared with those who had never been breast-fed. Although this relationship was attenuated it remained significant after adjusting for SES. However residual confounding from unmeasured social influences cannot be ruled out particularly when the attenuating affect is so strong. One recent study, supporting our finding, found suggestive evidence that breast-feeding during infancy was positively associated $(\mathrm{OR}=1 \cdot 26,95 \% \mathrm{CI} 1 \cdot 02,1 \cdot 55)$ with a healthy dietary pattern in Australian children aged 2-8 years ${ }^{(34)}$. A study in Scottish children aged 39-42 months published in 2002 found that the prevalence of obesity was significantly lower in breast-fed children and the association persisted after adjustment for SES, birth weight and gender ${ }^{(15)}$. The relationship between breast-feeding and overweight or obesity found in the present study was in the direction expected and as reported elsewhere ${ }^{(14,35-37)}$, however significance was borderline after adjusting for education and SES. Previous studies that have found evidence of a significantly lower prevalence of overweight or obesity due to breastfeeding suggest it is important to measure the dose and duration of breast-feeding ${ }^{(9,14,35-38)}$.

\section{Age of starting complementary feeding}

Infants who started complementary feeding at the age of 6-10 months or $4-5$ months were respectively $50 \%$ and $32 \%$ more likely to be in Cluster 2 compared with children who started complementary feeding very early, at 0-3 months. We are unaware of any published papers to date that have investigated the association between eating pattern and age of starting complementary feeding. Those who started complementary feeding after 4 months, compared with 0-3 months, were less likely to be overweight or obese in their fourth year of life. There is observational evidence from other studies to support this finding, demonstrating that early complementary feeding is significantly associated with increased risk of overweight or obesity at age 3 years ${ }^{(39-41)}$.

The ideal age to start introducing complementary food is around 6 months as recommended by the Department of Health. In Scotland, it was found that $60 \%$ of the mothers started complementary feeding by 4 months ${ }^{(22)}$. This is consistent with the GUS data presented in the current paper, which revealed that $66 \%$ and $18 \%$ of infants started complementary feeding between 4-5 months and 6-10 months, respectively. The 2005 UK infant feeding survey found that $31 \%$ of mothers started complementary feeding between 4 and 5 months and only $2 \%$ of mothers started complementary feeding after 6 months ${ }^{(22)}$, which is much lower than observed in the GUS data.

\section{Socio-economic status}

In the current study we used the respondents' education and the national SIMD 2006 index to define SES and assess its impact on infant feeding and eating patterns in the second year of life. It is well recognised that in the UK, mothers who breast-feed tend to be older and hold higher levels of educational qualification ${ }^{(22)}$. Although there is a fairly substantial body of evidence that has explored the association of eating patterns with $\operatorname{SES}^{(8,34,42-45)}$ and education $^{(8,34,42,45,46)}$, there is less information immediately 
following infancy. It has been reported that children of younger mothers with lower levels of education were more likely to consume a diet based on convenience foods and foods high in fat, whereas a 'healthy' diet was positively associated with increased levels of maternal education ${ }^{(8,25)}$. A similar finding was observed in the present study. Eating patterns in the second year were strongly related to the main caregivers' level of education, with a larger proportion of older and more educated mothers belonging to Cluster 2, suggesting that education continues to be an important determinant of eating patterns beyond infancy.

The association observed between SIMD quintiles and eating patterns in the second year in our study are consistent with previously published data that have demonstrated associations with social inequalities in early diet ${ }^{(8)}$. The effect sizes were less for SIMD when compared with respondents' education, suggesting that although significant, SIMD was not such a strong determinant of eating patterns as education. It is not clear from research to date why education is so strongly linked to eating patterns. Perhaps caregivers of infants with higher education have stronger intentions to follow recommended guidelines for their infants. They may also have better access to and understanding of health promotion campaigns. Therefore an individual- or family-level based measure of SES, such as education, is likely to provide a better reflection of infant feeding ${ }^{(6,8)}$. However at the same time there is a need to acknowledge that in selfreported questionnaires as used here for the GUS survey, respondent bias can be a potential limitation to the findings due to better educated subjects reporting more favourable dietary behaviour in their children, in a manner consistent with societal expectations ${ }^{(47)}$. Nevertheless, from a public health point of view, a measure of arealevel SES such as SIMD can provide relative understanding of how social deprivation within an area can impact infant eating patterns.

\section{Study strengths and limitations}

The main strength is that the GUS study is a large, contemporary, prospective birth cohort study of a nationally representative sample ( $n$ 5217) of infants from the Scottish population. The attrition rate in the study analysis over time can be partly explained by those lost to followup in the study and partly by those with missing measurement data. The GUS User Guide for each sweep provides detailed analysis of the respondents' and non-respondents' characteristics ${ }^{(27-29)}$. In Sweep 1 the response rate was $63 \%$ as a percentage of all eligible infants identified for participation in the study. In Sweep 2 and Sweep 4 the response rates were $87 \%$ and $77 \%$, respectively, as a percentage of all Sweep 1 cases. To correct for non-response bias and unequal sample selection, the longitudinal non-response sample weight and the clustering and stratification weights have been used in the analysis reported here.
The infant feeding data were collected retrospectively in Sweep 1 when the infants were 9-12 months of age and therefore are dependent on the respondents' accurate recall. The validity and reliability of maternal recall for the timing of infant feeding data have been reported and should be considered in future research design ${ }^{(48)}$. The breast-feeding data were based on a question 'Was the child ever breast-fed?' and as such does not give information on the measure of exclusiveness or duration of breast-feeding. This is a limitation of the present study, as a number of researchers have reported that duration and the amount of breast milk are important in the protective effect of breast-feeding ${ }^{(20,36,49)}$. The mixing together of infants who hardly breast-fed with those breast-fed exclusively for months in the 'ever breast-fed' group could be the main reason why a strong protective effect of breast-feeding with weight status in the fourth year of life is not observed in the study reported here. Due to this concern, when the new GUS cohort started in January 2011, the breast-feeding question was improved to provide a precise measure.

The measure of BMI was used to define overweight or obese infants in the fourth year of life. This provides a well-accepted proxy estimate of obesity in population samples of this kind ${ }^{(50)}$. However it is not a direct measure of adiposity and therefore children who have BMI within the normal range but have a high proportion of body fat may not be identified as overweight or obese. Since there were roughly equal proportions of data missing from infants belonging to Cluster 1 and Cluster 2, it is likely that a direct measure of adiposity may have increased the sensitivity of detecting a significant association in the multivariate model looking at the relationship between eating pattern and weight status.

The dietary data collected in Sweep 2 when the children were 19-24 months old, to define the eating pattern clusters, were not a record of the whole diet but asked about consumption of key foods (e.g. fruits, vegetables and snack foods) and so it is important to note that the clusters are generated from a limited list of foods. The majority of nutrition-focused studies that have used clustering methods to determine dietary patterns seem to prefer the $k$-means ${ }^{(42,44,51)}$ or hierarchical Ward's ${ }^{(45,46,52)}$ cluster algorithms or principal component factor analysis $^{(8,34,43)}$ rather than the SPSS two-step cluster analysis to derive dietary patterns from FFQ. The main advantage of the SPSS two-step log-likelihood cluster analysis algorithm is that it can process both categorical and continuous variables and it assigns a child to one eating pattern group.

\section{Conclusions}

Infant feeding and eating patterns in very young children beyond the first year of life are likely to influence later eating habits and therefore may have an impact on 
later-life health outcomes, as they can leave an imprint on metabolic functions and behaviour. Results from the present study suggest infant feeding practice may be indicative of the type of diet taken in the toddler years. The introduction of complementary feeding at 4-5 months compared with 0-3 months was negatively associated with being overweight or obese. There are a number of factors influencing childhood obesity including maternal dietary intake during gestation and lactation ${ }^{(53,54)}$ and easy availability of a variety of healthy snacks and meal choices for pre-school children and their caregivers. Therefore it is sensible to consider the overall picture of early nutrition, i.e. breast-feeding, complementary feeding and eating patterns beyond the first year, when designing early interventions to improve nutrition and prevent obesity.

The results from the present study support the hypothesis that a positive start to nutrition during infancy, as defined by breast-feeding and timely complementary feeding, is more likely to track to a positive eating pattern in the second year.

\section{Acknowledgements}

This secondary data analysis of the Growing Up in Scotland (GUS) data set received no specific grant from any funding agency in the public, commercial or not-forprofit sector. There are no conflicts of interest. E.C.A. is the main author and carried out the statistical analysis; J.G. is a contributing author, provided statistical analysis input and developed the program for Fig. 1; A.S. is a contributing author, provided statistical analysis input and proofreading; J.A. is a contributing author and project lead. The authors would like to acknowledge the GUS Study Team for providing access to their data set to carry out the secondary data analysis.

\section{References}

1. Dahlen HG \& Homer CS (2010) Infant feeding in the first 12 weeks following birth: a comparison of patterns seen in Asian and non-Asian women in Australia. Women Birth 23, 22-28.

2. Webber L, Cooke L, Hill C et al. (2010) Associations between children's appetitive traits and maternal feeding practices. J Am Diet Assoc 110, 1718-1722.

3. Daniels LA, Magarey A, Battistutta D et al. (2009) The NOURISH randomised control trial: positive feeding practices and food preferences in early childhood - a primary prevention program for childhood obesity. BMC Public Health 9, 387.

4. Clark HR, Goyder E, Bissell P et al. (2007) How do parents' child-feeding behaviours influence child weight? Implications for childhood obesity policy. J Public Health (Oxf) 29, 132-141.

5. Hughes SO, Power TG, Orlet FJ et al. (2005) Revisiting a neglected construct: parenting styles in a child-feeding context. Appetite 44, 83-92.

6. Skafida V (2009) The relative importance of social class and maternal education for breast-feeding initiation. Public Health Nutr 12, 2285-2292.
7. Northstone K, Emmett P \& Rogers I (2008) Dietary patterns in pregnancy and associations with socio-demographic and lifestyle factors. Eur J Clin Nutr 62, 471-479.

8. Northstone K \& Emmett P (2005) Multivariate analysis of diet in children at four and seven years of age and associations with socio-demographic characteristics. Eur $J$ Clin Nutr 59, 751-760.

9. Bartok CJ \& Ventura AK (2009) Mechanisms underlying the association between breastfeeding and obesity. Int $J$ Pediatr Obes 4, 196-204.

10. Cohen RJ, Brown KH, Canahuati J et al. (1994) Effects of age of introduction of complementary foods on infant breast milk intake, total energy intake, and growth: a randomised intervention study in Honduras. Lancet 344 , 288-293.

11. Miralles O, Sanchez J, Palou A et al. (2006) A physiological role of breast milk leptin in body weight control in developing infants. Obesity (Silver Spring) 14 1371-1377.

12. Addessi E, Galloway AT, Visalberghi E et al. (2005) Specific social influences on the acceptance of novel foods in 2-5-year-old children. Appetite 45, 264-271.

13. Birch LL (1998) Development of food acceptance patterns in the first years of life. Proc Nutr Soc 57, 617-624.

14. Arenz S, Ruckerl R, Koletzko B et al. (2004) Breast-feeding and childhood obesity - a systematic review. Int $J$ Obes Relat Metab Disord 28, 1247-1256.

15. Armstrong J, Reilly JJ \& Child Health Information Team (2002) Breastfeeding and lowering the risk of childhood obesity. Lancet 359, 2003-2004.

16. Singhal A \& Lanigan J (2007) Breastfeeding, early growth and later obesity. Obes Rev $\mathbf{8}, 51-54$.

17. Baird J, Poole J, Robinson S et al. (2008) Milk feeding and dietary patterns predict weight and fat gains in infancy. Paediatr Perinat Epidemiol 22, 575-586.

18. Moorcroft KE, Marshall JL \& McCormick FM (2011) Association between timing of introducing solid foods and obesity in infancy and childhood: a systematic review. Matern Child Nutr 7, 3-26.

19. Kramer MS, Guo T, Platt RW et al. (2004) Feeding effects on growth during infancy. J Pediatr 145, 600-605.

20. Owen CG, Martin RM, Whincup PH et al. (2005) Effect of infant feeding on the risk of obesity across the life course: a quantitative review of published evidence. Pediatrics 115, 1367-1377.

21. Scottish Government (2010) Preventing Overweight and Obesity in Scotland: A Route Map Towards Healthy Weight. Edinburgh: Scottish Government.

22. Bolling K, Grant C, Hamlyn B et al. (2007) Infant Feeding Survey 2005. A Survey Conducted on Behalf of the Department of Health, the Scottish Executive, the National Assembly for Wales and the Department of Health, Social Services and Public Safety in Northern Ireland. London: The Stationery Office.

23. Webb KL, Lahti-Koski M, Rutishauser I et al. (2006) Consumption of 'extra' foods (energy-dense, nutrientpoor) among children aged 16-24 months from western Sydney, Australia. Public Health Nutr 9, 1035-1044.

24. World Health Organization (2003) Global Strategy for Infant and Young Child Feeding. Geneva: WHO.

25. Northstone K \& Emmett P (2008) Are dietary patterns stable throughout early and mid-childhood? A birth cohort study. Br J Nutr 100, 1069-1076.

26. Tipping S \& Power S (2008) Analysing Growing Up in Scotland Data by Local Authority - Possible Options. Working Paper Prepared as Part of the GUS Review. Edinburgh: Scottish Centre for Social Research.

27. Bradshaw P, Tipping S, Marryat L et al. (2007) Growing Up in Scotland Sweep 1: 2005 User Guide. Edinburgh: Scottish Centre for Social Research. 
28. Bradshaw P, Tipping S, Marryat L et al. (2008) Growing Up in Scotland Sweep 2: 2006-2007 User Guide. Edinburgh: Scottish Centre for Social Research.

29. Bradshaw P, Marryat L, Corbett J et al. (2010) Growing Up in Scotland Sweep 4: 2008-2009 User Guide. Edinburgh: Scottish Centre for Social Research.

30. World Health Organization (2005) Guiding Principles for Feeding Non-breastfed Children 6-24 months of Age. Geneva: WHO.

31. Cole TJ, Freeman JV \& Preece MA (1995) Body mass index reference curves for the UK, 1990. Arch Dis Child 73, 25-29.

32. Birch LL (1999) Development of food preferences. Annu Rev Nutr 19, 41-62.

33. Birch LL (2006) Child feeding practices and the etiology of obesity. Obesity (Silver Spring) 14, 343-344.

34. Grieger JA, Scott J \& Cobiac L (2011) Dietary patterns and breast-feeding in Australian children. Public Health Nutr 14, 1939-1947.

35. Owen CG, Martin RM, Whincup PH et al. (2005) The effect of breastfeeding on mean body mass index throughout life: a quantitative review of published and unpublished observational evidence. Am J Clin Nutr 82, 1298-1307.

36. Harder T, Bergmann R, Kallischnigg G et al. (2005) Duration of breastfeeding and risk of overweight: a metaanalysis. Am J Epidemiol 162, 397-403.

37. von Kries R, Koletzko B, Sauerwald T et al. (1999) Breast feeding and obesity: cross sectional study. BMJ 319, $147-150$.

38. World Health Organization (2007) Evidence on the Longterm Effects of Breast Feeding: Systematic Reviews and Meta-Analyses. Geneva: WHO.

39. Huh SY, Rifas-Shiman SL, Taveras EM et al. (2011) Timing of solid food introduction and risk of obesity in preschoolaged children. Pediatrics 127, e544-e551.

40. Seach KA, Dharmage SC, Lowe AJ et al. (2010) Delayed introduction of solid feeding reduces child overweight and obesity at 10 years. Int J Obes (Lond) 34, 1475-1479.

41. Hawkins SS, Cole TJ, Law C; Millennium Cohort Study Child Health Group (2009) An ecological systems approach to examining risk factors for early childhood overweight: findings from the UK Millennium Cohort Study. J Epidemiol Community Health 63, 147-155.
42. Smith AD, Emmett PM, Newby PK et al. (2011) A comparison of dietary patterns derived by cluster and principal components analysis in a UK cohort of children. Eur J Clin Nutr 65, 1102-1109.

43. Kant AK, Graubard BI \& Schatzkin A (2004) Dietary patterns predict mortality in a national cohort: the National Health Interview Surveys, 1987 and 1992. J Nutr 134, 1793-1799.

44. Villegas R, Salim A, Collins MM et al. (2004) Dietary patterns in middle-aged Irish men and women defined by cluster analysis. Public Health Nutr 7, 1017-1024.

45. Pryer JA \& Rogers S (2009) Dietary patterns among a national sample of British children aged $1 \frac{1}{2}-4 \frac{1}{2}$ years. Public Health Nutr 12, 957-966.

46. Knol LL, Haughton B \& Fitzhugh EC (2005) Dietary patterns of young, low-income US children. J Am Diet Assoc 105, 1765-1773.

47. Hebert JR, Hurley TG, Peterson KE et al. (2008) Social desirability trait influences on self-reported dietary measures among diverse participants in a multicenter multiple risk factor trial. J Nutr 138, issue 1, 226S-234S.

48. Li R, Scanlon KS \& Serdula MK (2005) The validity and reliability of maternal recall of breastfeeding practice. Nutr Rev 63, 103-110.

49. Bogen DL, Hanusa BH \& Whitaker RC (2004) The effect of breast feeding with and without formula use on the risk of obesity at 4 years of age. Obes Res 12, 1527-1535.

50. Reilly JJ, Dorosty AR, Emmett PM, ALSPAC Study Team (2000) Identification of the obese child: adequacy of the BMI for clinical practice and epidemiology. Int J Obes Relat Metab Disord 24, 1623-1627.

51. O'Connor TM, Hughes SO, Watson KB et al. (2010) Parenting practices are associated with fruit and vegetable consumption in pre-school children. Public Health Nutr 13, 91-101.

52. Lee JW, Hwang J \& Cho HS (2007) Dietary patterns of children and adolescents analyzed from 2001 Korea National Health and Nutrition Survey. Nutr Res Pract 1, 84-88.

53. Lucas A (1994) Role of nutritional programming in determining adult morbidity. Arch Dis Child 71, 288-290.

54. Monasta L, Batty GD, Cattaneo A et al. (2010) Early-life determinants of overweight and obesity: a review of systematic reviews. Obes Rev 11, 695-708. 